\title{
SPATIAL STRUCTURE OF URBAN LANDUSE IN KATHMANDU VALLEY
}

\author{
Shobha Shrestha, PhD
}

Keywords: Urban landuse change, spatial structure, landuse fragmentation, spatial metrics, GIS and RS

\begin{abstract}
Spatial structure of urban land use has been interest of study since early 20th century. The current study examines dynamics of spatial structure of urban agricultural landuse and how agricultural landuse is placed within the existing structure. The study explores the direction and dimension of landuse change and characteristics of spatial fragmentation in Kathmandu Valley. Technological tools like GIS and Remote Sensing, and Spatial metrics/indices has been used for spatial analysis. The study shows that within ten years time span of 2003 to 2012 , urban land use has gone drastic change in Kathmandu valley. Remarkable change in terms of pace and direction is evident in agriculture and built-up classes which signifies the rapid urbanization trend in the valley. The finding shows that spatial structure of the urban landuse of the valley is impending towards more heterogeneous and diverse landscape. Similarly, spatial fragmentation analysis highlights characteristic development of new isolated urban patches inside relatively larger agriculture patches fragmenting them into number of smaller patches. The study concludes that the importance of GIS/RS tools and technology in identifying and analyzing structure and dynamics of land use within prevailing complex urban system of Kathmandu valley is reasonable. The composition and configuration of spatial structure computed through spatial metrics are thus helpful for understanding how landscape develops and changes over time.
\end{abstract}

\section{OBJECTIVE:}

The objective of the current study is to explore to what extent and how the spatial structure of urban landuse has changed between 2003 - 2012.

\section{METHODOLOGY:}

The current study has used integrative methodology of combined use of remote sensing, GIS and spatial metrics which is relatively new approach and has shown considerable potential for structural analysis of urban environments (Torrens, 2008). The current research has used integrated methodology. Exploratory descriptive and analytical framework is adopted for spatial assessment. Tools and techniques applied are documentary review, Remote Sensing and GIS based mapping and spatial metrics. Qualitative and quantitative analysis using both primary and secondary sources for data and information collection is carried out depending upon nature and type of data and information collected. Through field observation and informal discussions are carried out in the field. Kathmandu valley is selected as a study area. It is selected as study area because despite being the most urbanized area and capital region of the country, it embraces heterogeneous land use including larger coverage of agricultural land. Digital database created from satellite images of different temporal and spatial resolutions are the major sources for bio-physical land use/land cover and agriculture data. Urban land use/land cover change from 2003 to 2012 was carried out using high resolution remote sensing images of three time period: 2003, 2007 and 2012. For the time period 2003 and 2006/7 Quick Bird images with spatial resolution less than 1meter were used. For 2012, ResourceSAT images of December, with 5meter spatial resolution from Indian Remote Sensing organization, IRS was used to identify/analyze more recent structure and dynamics of urban land cover/land use in the study area. Multi spectral analysis included digital classification of land use. At least ten training sample sites were selected for each land use class and these sampling sites were field verified. Major visible changes were noticed and verified through informal conversation with locals of the study area. GIS maps and satellite images of different time periods were used as field verification tools and land cover/land use found on the ground and in the map/images compared. Final landuse data layer of each time period was produced with six major land use classes as specified in topographical sheets from Survey Department of Nepal

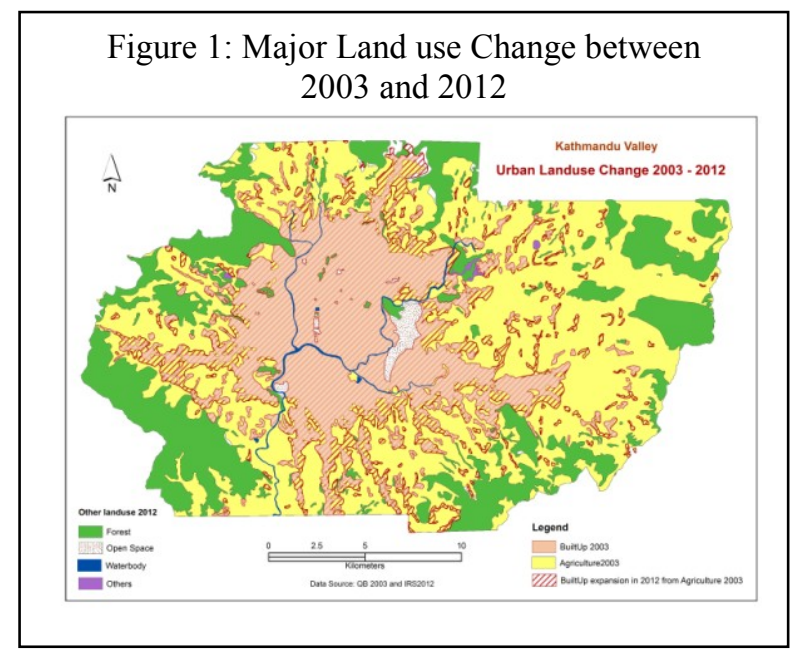

namely, agriculture, built-up, forest, open spaces 
including barren land, water body and other which includes all except aforementioned classes. Land use change analysis is carried out overlaying landuse data layers and change from one class to another is calculated and spatial analysis carried out based on the GIS output map and table.

Another tool used is spatial metrics for fragmentation and heterogeneity analysis. The spatial metrics is quantitative measures of spatial pattern and composition which describe the spatial heterogeneity for each land use class. Spatial metrics derived from satellite imagery also help to describe the morphological characteristics of urban areas and their changes through time. Spatial metrics as discussed by Eric J. Gustafson (1998) is used in this study for analysis of spatial structural morphology and heterogeneity of urban land use in Kathmandu valley during different periods. The indices developed by McGarigal (McGarigal et. al., 1995) used. Landscape level valley level for overall fragmentation and heterogeneity analysis and landuse individual class level analysis were carried out to quantify shape and pattern of urban landuse in the study area which measures fragmentation, dominance, proximity and diversity. Selected spatial metrics includes spatial Indices measuring composition and spatial configuration. Composition is quantified, and is described by:

(a) Number of landuse classes in the data/map, (b) Proportion of each class relative to the data/map, and (c) Diversity which combines two components of diversity: richness, which refers to the number of classes present, and evenness, which refers to the distribution of area among the classes.

Simpson's (Simpson, 1949) diversity index is example of such. The spatial configuration of structure properties is much more difficult to quantify, and attempts have focused on describing spatial characteristics of individual patches (patch based) and the spatial relationships among multiple patches (neighborhood based). Patch-based measures of pattern include size, number, and density of patches. These measures are calculated for all classes together or for a particular class of interest. Similarly, edge information includes various edges metric that incorporate the contrast (degree of dissimilarity) between the patch and its neighbors.

\section{OVERVIEW OF URBAN LAND USE CHANGE 2003 -2012:}

Number of studies focusing on urban land cover/land use issues of Kathmandu valley has been carried out using GIS and RS tools in different time period (Tamrakar, 1998; Koirala, 1999; Pradhan, 2001; Paudel \& Karki, 2005; Haack \& Rafter, 2006; Hack, 2009; Hack \& Khatiwada, 2007; ICIMOD, 2007; Ghimire, 2008; Thapa \& Murayama, 2009, 2010;
Zurick, 2010; Rimal, 2011). These studies show accelerating urban growth of the valley resulting significant change in land use structure. Spatial expansion of Kathmandu city from historical period and change in morphological characteristics had also been explored (Ranjitkar \& Manandhar, 1981). Directional expansion towards east and on patches as multiple nuclei are major characteristics from 1846 to 1964 whereas construction of road infrastructure (particularly Ring road) is characteristics after 1977 causing overall change in morphological structure of the city.

Direction and dimension of change in land cover/ land use class between 2003, 2007 and 2012 in Kathmandu valley is shown in figure 1 and detailed in table 1.

The table reveals that within ten years time span land use has gone drastic change. Remarkable change is evident in agriculture and built-up classes which signifies the rapid urbanization trend in the valley. Agriculture land coverage has decreased from 52.5 percent to 44 percent whereas built-up area has increased from 23 percent to 31.5 percent. As compared to agriculture and built-up area, forest area has remained relatively constant covering 22 percent of the valley. Major land use conversion observed during all three period is agriculture and built up classes. Most of the agriculture lands next to the core area followed by surrounding agriculture area have been converted to urban built-up during the decadal period of 2003-2012.

\begin{tabular}{|c|c|c|c|c|}
\hline & \multicolumn{4}{|c|}{$\begin{array}{l}\text { Table 1: Kathmandu valley Landuse change } \\
\text { Statistics } 2003-2012\end{array}$} \\
\hline $\mathrm{SN}$ & $\begin{array}{l}\text { Land use } \\
\text { Class }\end{array}$ & $\begin{array}{c}2003 \\
(\%)\end{array}$ & $\begin{array}{c}2007 \\
(\%)\end{array}$ & $\begin{array}{c}2012 \\
(\%)\end{array}$ \\
\hline 1 & Agriculture & 52.58 & 46.58 & 44.70 \\
\hline 2 & Built up & 23.25 & 29.59 & 31.54 \\
\hline 3 & Forest & 22.61 & 22.35 & 22.20 \\
\hline 4 & Open Space & 0.93 & 0.90 & 0.93 \\
\hline 5 & Water Body & 0.15 & 0.12 & 0.15 \\
\hline \multirow[t]{2}{*}{6} & Others & 0.45 & 0.45 & 0.45 \\
\hline & Total & 99.98 & 99.98 & 99.97 \\
\hline
\end{tabular}

Source: Calculated from GIS data (satellite image QB 2003, 2007 and IRS 2012)

\section{MORPHOLOGY AND STRUCTURE OF URBAN LANDUSE: FRAGMENTATION AND HETEROGENEITY ANALYSIS:}

Spatial structure is a major subset of the concept of spatial heterogeneity which refers to the spatial configuration of the landscape. In this section, morphological dynamics i.e. spatial fragmentation and heterogeneity analysis at landscape level (i.e. heterogeneity among all types of land use existing within the valley, which provides overview of spatial heterogeneity) is carried out for Kathmandu valley 
using land use data of three different periods (2003, 2007 and 2012).

At the landscape level, Patch density (PD), Edge density (ED), Largest patch index (LPI), Perimeterarea fractal dimension ratio (PAFRAC), Euclidian nearest neighbour area weighted mean (ENN_AM), Contagion index $(\mathrm{CI})$, Patch cohesion index (PCI), Landscape division index (LDI) and Simpson's diversity index (SIDI) are calculated to assess heterogeneity and fragmentation in spatial structure of land use.

PD has increased gradually from 0.812 to 1.008 at the landscape level, indicating the growth of new patches. With the development of new patches, new edge segments are created which is visible from increasing ED value of three time periods. The gradual increase in PD and ED value shows fragmentation of agricultural patches with new residential developments. The positive correlation between LPI and PD (increasing patch density and decreasing size of largest patch) is also evident from the table 2 .

Calculated LPI value shows that the size of largest patch has decreased from 34 to 27 . This indicates the decrease in size and increase in fragmentation. Variable proximity (variable ENN value) is another characteristics showing reducing proximity between 2003 and 2007 and relatively lower reduction between 2007 and 2012. Between 2003 and 2007 new isolated urban patches developed in relatively larger agriculture patches increasing distance between urban patches whereas expansion of urban area in the existing builtup periphery and expansion of isolated patches merged into one-another between 2007 and 2012 decreasing the distance between urban patches. This is also evident from the variable value of perimeter-area fractal ratio. Though the decreasing value between 2003 and 2007 shows connected expansion of urban area in the existing built-up, shape of patches became more complex between 2003 and 2012 (figure 2).

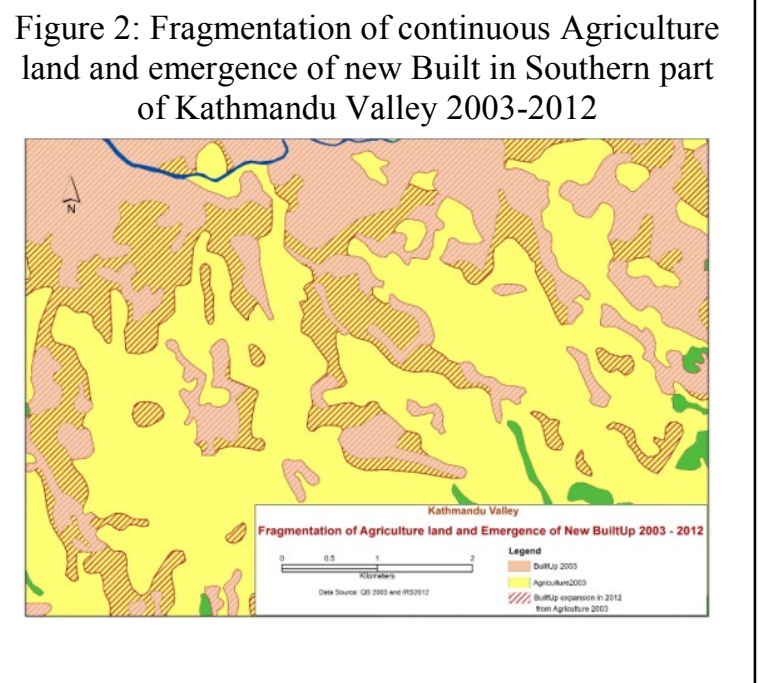

Contagion index on the other hand shows the increasing fragmentation of patches as decreasing index value shows increasing disaggregated patches. Highest difference between 2003 and 2012 shows increasing disaggregated patches as compared to 2007 and 2012. The evidence of increasing number of disaggregated patches is marked by patch cohesion index value. The decreasing value highlights gradual decreasing of physical connectedness. Increasing landscape division index values exemplify further fragmentation of landscape into smaller patches and decrease in proportional patch sizes. Simpson's diversity index value indicates increasing heterogeneity within urban landscape. Relatively higher difference value between 2003 and 2007 also shows increased heterogeneity. On the other side, moderate value between 2007 and 2012 indicates comparative homogeneity due to expansion of built-up areas through guided land development and organized housing by private companies.

Spatial fragmentation and heterogeneity analysis reveal that the urbanization process resulted mostly in

\begin{tabular}{|c|c|c|c|}
\hline Year & $\begin{array}{l}\text { Patch } \\
\text { Density } \\
(\mathrm{PD})\end{array}$ & $\begin{array}{l}\text { Largest } \\
\text { Patch Index } \\
(\mathrm{LPI})\end{array}$ & $\begin{array}{l}\text { Edge } \\
\text { Density } \\
\text { (ED) }\end{array}$ \\
\hline 2012 & 1.008 & 27.485 & 28.806 \\
\hline 2007 & 0.936 & 29.583 & 27.551 \\
\hline 2003 & 0.812 & 34.994 & 25.645 \\
\hline Value & Increasing & Decreasing & Increasing \\
\hline Year & $\begin{array}{l}\text { Contagion } \\
\text { index }(\mathrm{CI})\end{array}$ & $\begin{array}{l}\text { Patch } \\
\text { cohesion } \\
\text { index (PCI) }\end{array}$ & $\begin{array}{l}\text { Landscape } \\
\text { division } \\
\text { index (LDI) }\end{array}$ \\
\hline 2012 & 60.019 & 99.323 & 0.839 \\
\hline 2007 & 60.307 & 99.358 & 0.836 \\
\hline 2003 & 61.987 & 99.394 & 0.819 \\
\hline Value & Decreasing & Decreasing & Increasing \\
\hline Year & $\begin{array}{l}\text { Perimeter } \\
\text { Area } \\
\text { Fractal } \\
\text { dimension } \\
\text { Ratio } \\
\text { (PAFRAC) }\end{array}$ & $\begin{array}{l}\text { Euclidean } \\
\text { nearest } \\
\text { neighbor } \\
\text { area } \\
\text { weighted } \\
\text { mean } \\
\text { (ENN-AM) }\end{array}$ & $\begin{array}{l}\text { Simpson's } \\
\text { diversity } \\
\text { index(SIDI) }\end{array}$ \\
\hline 2012 & 1.375 & 134.123 & 0.649 \\
\hline 2007 & 1.369 & 141.072 & 0.645 \\
\hline 2003 & 1.370 & 132.606 & 0.617 \\
\hline Value & Variable & Variable & Increasing \\
\hline \multicolumn{4}{|c|}{$\begin{array}{l}\text { Source: Calculated from GIS data (satellite image } \\
\text { QB 2003, } 2007 \text { and IRS 2012) }\end{array}$} \\
\hline
\end{tabular}

previously agricultural dominant lands and has caused fragmentation. The land use patch density significantly increased during the period of 2003- 2012. This has 
resulted heterogeneous and diverse land use within urban landscape of the valley. With the increasing urbanization, land use structure undergoes changes in their shape and size (Thapa and Murayama, 2010). Spatial heterogeneity is ubiquitous in urban landscape and its formation and interaction with urban process is central issue in urban land use dynamics.

\section{SUMMARY \& CONCLUSION:}

Within ten years time span of 2003 to 2012, urban land use has gone drastic change in Kathmandu valley. Remarkable change in terms of pace and direction is evident in agriculture and built-up classes which signifies the rapid urbanization trend in the valley. Agriculture land coverage has decreased from 52.6 percent to 44 percent whereas built-up area has increased from 23 percent to 31 percent between 2003 and 2012. Most of the agriculture lands next to the built-up core area followed by surrounding agriculture area have been converted to urban built-up during the decadal period of 2003-2012. Spatial pattern of urban growth is radial around road network and expansion is in all direction. Noticeable urban growth is visible in three different parts of the valley, central north, centraleast and western-south. Despite all spatial dynamics and decrease of agricultural landuse due to urban expansion in Kathmandu valley, the overall spatial extent of urban agricultural land use still holds 44 percent of total area and thus remained as significant urban landscape for decades.

Spatial fragmentation and heterogeneity analysis of landuse at landscape and class level carried out using spatial metrics found that the urbanization process resulted mostly in previously agricultural dominant lands and has caused fragmentation. The size of largest patch has decreased from 34 to 27 percent between 2003 and 2012 showing decrease in size and increase in fragmentation. Spatial structure of the urban landuse of Kathmandu valley is hence impending towards more heterogeneous and diverse landscape. Similarly, the resultant spatial heterogeneity of land use at class level structure is characterized by development of new isolated urban patches in relatively larger agriculture patches separating them. Connected expansion of existing built-up in the periphery and merging of isolated patches into one-another decreasing the distance between built-up patches is also evident. The evidence of increasing number of disaggregated patches and more complex shape is also marked.

The importance of GIS/RS tools and technology in identifying and analyzing structure and dynamics of land use within prevailing complex urban system of Kathmandu valley is reasonable. The composition and configuration of spatial structure computed through spatial metrics are thus helpful for understanding how landscape develops and changes over time.
References:

Ghimire, H. (2008). An assessment of the environmental problems in the Kathmandu Valley of Nepal. Unpublished Master's Thesis. Institute of Environmental Sciences. Miami University.Miami.

Gustafson, E. J. (1998). Quantifying Landscape Spatial Pattern: What Is the State of the Art? Ecosystems, 1 (2), 143-156.

Haack, B. (2009). A History and Analysis of Mapping Urban Expansion in the Kathmandu Valley, Nepal. The Cartographic Journal, 46 (3). 233-241.

Haack B. \& Khatiwada, G. (2007). Rice and Bricks: Environmental Issues and Mapping of the Unusual Crop Rotation Pattern in the Kathmandu Valley, Nepal. Environmental Management, 39.774-782.

Haack B. \& Rafter, A. (2006). Urban growth analysis and modeling in the Kathmandu Valley, Nepal. Habitat International 30. 1056-1065.

Koirala, H. (1999). Issues of urban environment in Kathmandu valley: A case study of Kathmandu Metropolitan city. The Himalayan Review, XXXIII, 118.

McGarigal, K., \& Marks, B. J. (1995). FRAGSTATS: Spatial pattern analysis program for quantifying landscape structure. Technical Report PNW-GTR-351, USDA Forest Service, Pacific Northwest Research Station, Portland, Oregon.

Paudel, J. R., \& Karki, S. (2005). Study of change in urban landuse. Geo-informatics, 4, pp -??.

Pradhan, P. K. (2001). Population growth, migration and urbanization and environmental change in Kathmandu Valley, Nepal. Proceedings of International Conference on Environmental change: Implications for population migrations. Switzerland.

Ranjitkar, N. G., \& Mannandhar, M. S. (1981). Spatial expansion of Kathmandu city. Geographical Journal of Nepal, 3-4, 25-35

Rimal, B. (2011). Landuse change analysis of Kathmandu Metropolitan using remote sensing and geographic information system. Geo Spatial World.

Tamrakar, T. (1998). Urban Growth, Land Use Change and Impact on Environment: A Case Study of Kathmandu Valley. Unpublished Postgraduate thesis, CSSTE-AP, Dehradun. 
Thapa, R. B., \& Yuji, M. (2010). Drivers of urban growth in the Kathmandu valley, Nepal: Examining the efficacy of the analytic hierarchy process. Applied Geography, 30, 70-83.

Thapa, R. B., \& Yuji, M. (2009). Examining spatiotemporal urbanization patterns in Kathmandu Valley, Nepal: Remote sensing and spatial matrices approaches. Remote Sensing, 1, 534-556.

Torrens, P. M. 2008. A toolkit for measuring sprawl. Applied Spatial Analysis and Policy 1(1):5-36.

\begin{tabular}{|l|l|}
\hline & \\
\hline Name: & Author's Information \\
Academic Qualification: & $\begin{array}{l}\text { Ms. Shova Shrestha } \\
\text { Organization: }\end{array}$ \\
& $\begin{array}{l}\text { Central Department of } \\
\text { Geography, TU } \\
\text { Current Designation: }\end{array}$ \\
$\begin{array}{l}\text { Wocturer } \\
\text { 15 years }\end{array}$ \\
$\begin{array}{l}\text { Published Papers/Articles: NA } \\
\text { e-mail: }\end{array}$ & shova216@gmail.com \\
\end{tabular}

